\title{
Orbital Metastasis of Esophageal Squamous Cell Carcinoma
}

\author{
Kei Iimori, Tadayuki Kou and Shujiro Yazumi
}

Key words: Esophagus, extraocular muscles, orbital tumors

(Intern Med 60: 1475-1476, 2021)

(DOI: 10.2169/internalmedicine.6291-20)

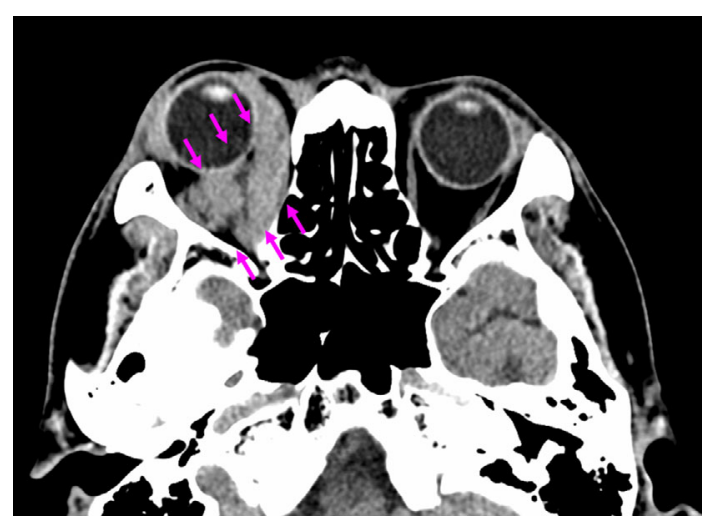

Picture 1.

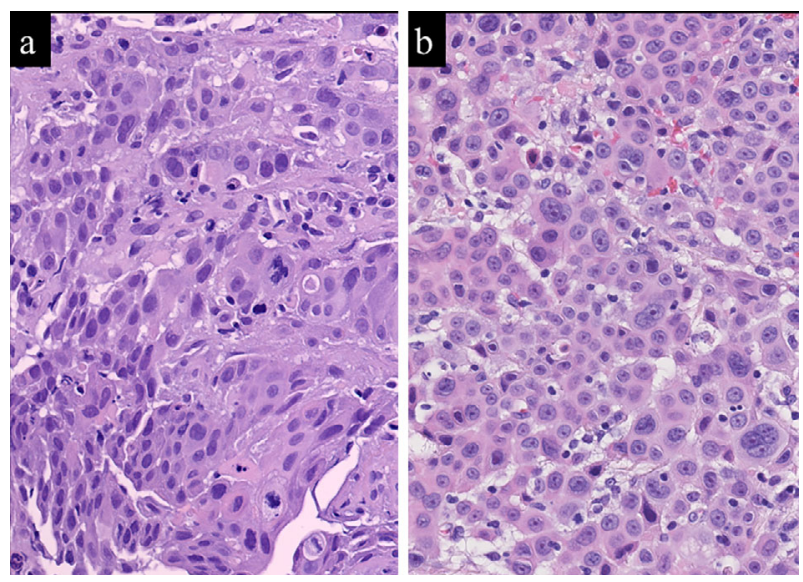

Picture 3.

A 65-year-old man presented with diplopia. A neurological examination revealed periorbital swelling and movement disorder of the right eye due to abnormalities of the right extraocular muscles. Computed tomography showed a masslike lesion involving the extraocular muscles in the right orbit (Picture 1, arrows). Upper gastrointestinal endoscopy revealed a 20 -mm type 2 tumor with spontaneous blood ooz-

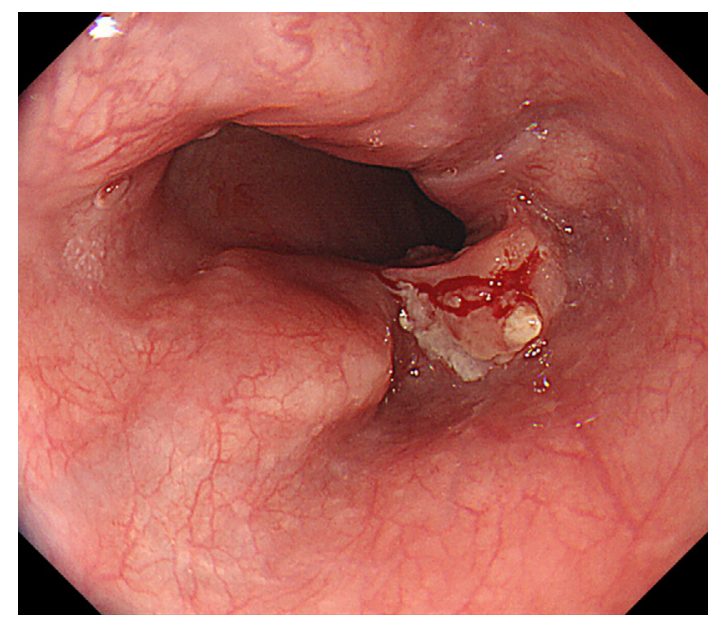

Picture 2.

ing in the middle thoracic esophagus (Picture 2). A biopsy specimen revealed moderately differentiated squamous cell carcinoma (SCC) of the esophagus (Picture 3a). A subsequent biopsy specimen obtained from the right eye revealed poorly differentiated SCC (Picture 3b), which was compatible with metastasis of esophageal SCC (ESCC) to the orbit. One course of 5-fluorouracil plus cisplatin was administered; however, the patient's condition deteriorated rapidly, and he ultimately received palliative care. Metastatic orbital tumors account for only approximately 3\% of all reported orbital tumors (1). The most frequent primary site of orbital metastasis is breast cancer (2), and to our knowledge, only four cases of orbital metastasis of ESCC have been reported. In the present case, ocular symptoms were the initial manifestation of ESCC.

The authors state that they have no Conflict of Interest (COI).

\section{References}

1. Bonavolontà G, Strianese $D$, Grassi $P$, et al. An analysis of 2,480

Department of Gastroenterology and Hepatology, Tazuke Kofukai Medical Research Institute, Kitano Hospital, Japan Received: September 12, 2020; Accepted: September 24, 2020; Advance Publication by J-STAGE: November 16, 2020 Correspondence to Dr. Shujiro Yazumi, s-yazumi@kitano-hp.or.jp 
space-occupying lesions of the orbit from 1976 to 2011. Ophthalmic Plast Reconstr Surg 29: 79-86, 2013.

2. Amemiya T, Hayashida H, Dake Y. Metastatic orbital tumors in Japan: a review of the literature. Ophthalmic Epidemiol 9: 35-47, 2002.
The Internal Medicine is an Open Access journal distributed under the Creative Commons Attribution-NonCommercial-NoDerivatives 4.0 International License. To view the details of this license, please visit (https://creativecommons.org/licenses/ by-nc-nd/4.0/).

(C) 2021 The Japanese Society of Internal Medicine Intern Med 60: 1475-1476, 2021 